\title{
Tribhuvan University certificate nursing curriculum
}

\author{
K. Regmi, ${ }^{1}$ S Regmi, ${ }^{2}$ M. Shahi. ${ }^{3}$ \\ ${ }^{1}$ University of the West of England, Bristol, UK. ${ }^{2}$ Royal Berkshire NHS Foundation Hospital, Reading, UK. ${ }^{3}$ Medical \\ Education Department, Institute of Medicine, TU, Kathmandu, Nepal.
}

Correspondence to :Krishna Regmi, University of the West of England, Bristol, UK

Email:kregmi@yahoo.com

\begin{abstract}
Introduction: A Nepalese certificate of nursing curriculum was developed in 1977 and has been used since with a few revisions. There has been open debate about continuing gaps between theory, as expressed in the curriculum, and practice. The purpose of this study was to evaluate this 3-year undergraduate curriculum, and to draw general lessons, which might help to develop appropriate strategies to improve nursing education in Nepal.

Methods: A mixed evaluation method was used consisting of reviews of current curriculum theories/ models, and interviews with nursing students (15) and nursing tutors (10).

Results: Both students and tutors were generally positive about the curriculum and its intended learning outcomes. While reviewing the existing curriculum, analysis revealed that there was limited use of curriculum theories and models.

Conclusions: There is a need to focus more on the development of abilities related to evidencebased learning. Selection of appropriate teaching-learning methodologies in response to the growing needs of students and professionals, development of learning strategies to reduce the gap between educational theories and nursing practice, in line with a humanistic paradigm in nursing education is important.
\end{abstract}

Keywords: Curriculum evaluation, Nepal, nurses, nursing education.

\section{Introduction}

Nursing is a practice discipline. Since the beginning of nursing education in 1956, there was always a shortage of nurses in Nepal due to inefficient education policy. ${ }^{1}$ The certificate of nursing curriculum, which is the focus of this paper, was developed in 1977 and has been used since with a few revisions. A continuing gap between curriculum theory and practice has been openly debated among nursing graduates and nursing lecturers. The aim of this paper was to analyse and evaluate the 3-year undergraduate certificate of nursing curriculum using different curriculum theories, models and ideologies as well as interviews with selected students and (tutors) lecturers. ${ }^{1}$
Some fifty years ago there was neither a university nor medical education in Nepal. Prior to 1950, Nepal was isolated from the outside world. ${ }^{2}$ There were no public health programmes, few hospitals, less than a dozen Nepalese doctors and no Nepalese nurses. ${ }^{2}$ The Civil Medical School was started in 1934 for the training of compounders and dressers. Nursing education began in 1956 under the Ministry of Health $(\mathrm{MoH})$ at Surendra Bhawan (Sanepa) and the growth in terms of education and development remained quite slow. ${ }^{3-5}$ The school moved from Sanepa to Mahabauddha to Maharajgunj in quick succession as compared to upgrading of the education. New curricula, implemented at the certificate level in 1987 and the bachelor level in 1989, focused on preparing nurses for a variety of 
roles in primary health care. ${ }^{3,6,7}$ There was a strong shift in focus at the certificate level to emphasize potential roles in community health and at the bachelor level to concentrate on development of leadership skills. ${ }^{1}$ Most nurses, however, are employed in hospitals, and current Government plans demonstrate little interest in creating community health nursing jobs. ${ }^{8}$ It took almost 20 years to upgrade from certificate of nursing in 1956 to post-basic bachelor degree in midwifery in nursing in $1976 .{ }^{3}$ It took almost another two decades to move into the master in nursing. ${ }^{3}$ Responding to the call of the time, nursing education underwent quantitative and qualitative changes. ${ }^{1}$

The principal aims of nursing education are to transfer nursing knowledge and to assist students to acquire the essential skills and attitudes associated with nursing practice. ${ }^{9}$ As with professional preparation generally, nursing education encompasses the three domains of learning, the cognitive, the affective, and the psychomotor. ${ }^{9}$ At the philosophical level, there was an attempt to define nursing in the Nepalese context. ${ }^{1}$ Changing the curriculum to focus on community health implies dissatisfaction with the status quo and an attempt to broaden the scope of nursing. ${ }^{1,10}$

The certificate of nursing curriculum in its early days (1970s to 1980s) was a body of subject matter set out by teachers for students to cover. ${ }^{1}$ The curriculum, which is the focus of this paper, was first developed in 1977 and has been used since with a few minor revisions in $1987 .{ }^{1}$ It has been last revised in 2007, the latter moving towards a more processorientation approach to teaching and learning. ${ }^{1,3} \mathrm{~A}$ succession of shifting demands and priorities, and the theory of education of the time, compelled continuous change of the curriculum. ${ }^{6}$ The focus of the nursing curriculum has shifted from being subject-centred to student-centred and from individual-focused to community-focused, the latter moving towards a more process-orientation approach to teaching and learning. ${ }^{1}$ Barret et al. claimed that a community-based curriculum is considered as one that responds to the needs of community care. ${ }^{11}$

The latest curriculum handbook describes the course in detail and the subjects involved. At present, the certificate of nursing programme referred to is a three-year academic programme based at different nursing campuses under the Institute of Medicine in Nepal, and accredited by the Government of Nepal. ${ }^{1}$ The curriculum is designed as a community oriented nursing programme with the philosophy of health for all and employs primary health care (PHC) strategies. ${ }^{1,3}$ Also, the "concepts of primary, secondary, and tertiary prevention are integrated throughout the nursing curriculum with the intention of producing nurses equipped with the necessary knowledge and skills to provide essential health services to individuals and families in hospital and primary care settings. ${ }^{12}$ The programme has a common core of both theoretical and clinical/community practical mix that leads to a Certificate of Nursing Education and it also qualifies staff nurses in a variety of positions, such as district nurse, community health nurse, public health nurse and so on. ${ }^{1,3,6}$ The existing nursing curriculum has been successful in providing a foundation on which Bachelor and Masters level nursing curricula are built. Following completion of their nursing education programme, nurses will be registered with the Nepal Nursing Council. ${ }^{7}$ This registration is the equivalent of the Registered Nurse (RN) and serves as licence to practice. ${ }^{13}$

The concept of curriculum ranges from a 'descriptive plan or design upon which educational provision' is based to following a course of papers. ${ }^{14,15}$ As Pratt notes, much of the curriculum research of the 1970s points to the need for design 'intended to have educational consequences for students.' Time, context and empirical experiment have shown that if education is to be effective and creative, all aspects of curricula should be considered with care and imagination. ${ }^{16,17}$ It has been suggested that within the philosophy of curriculum, skills of critical analysis and problem solving should be developed. ${ }^{18-20}$ Toffler argues that "nothing should be included in a required curriculum unless it can be strongly justified in terms of meeting the needs and expectations of learners. ${ }^{21}$ Thus, it can be argued that curricula should develop with a new philosophy to accommodate rapid, unpredictable changes both in educational objectives, processes and contents. Prominent changes can be shown, such as a shift of focus from a curriculum-driven model to a model that focuses on: learners and creation of a climate for life-long learning; the cancellation of traditional student evaluation tools; and the integration of areas of learning through projects and themes. ${ }^{14}$

Education can be defined as the art of acquiring, retaining and utilizing knowledge at a required time. Knowledge is information plus experience. ${ }^{22}$ Education in nursing is a complex subject, as it represents a mixture of theory evolved in a variety of disciplines to be used and applied in care settings. ${ }^{9,23}$ Preparing nurses to cope with a complex, uncertain and dynamic health care system cannot be achieved only through a highly structured and pre-planned curriculum. ${ }^{24}$ It is therefore claimed that a more flexible and integrative learning approach would be a strong attribute in the evaluation of any education curricula. ${ }^{9}$

In the changing context of nursing education in Nepal, Jolley 
and Hegge argued that the required restructure in nursing education has to be compatible with the innovative mechanisms in academia, for example evidence-based and competency-based learning. ${ }^{25,26}$ Based on curriculum philosophy, it can be argued that the new education trends (evidence-based learning, students centred approach) in nursing education need to be changed. ${ }^{27}$ Booth and Hegge call for curriculum evaluation in terms of its overall 'content' and 'processes'. ${ }^{26,28}$ As in different parts of the world, nursing roles and responsibility for nursing care are also shifting from hospital to community care. ${ }^{8}$ It is, therefore, well recognised that there has been a need for introducing more changes to curricula. ${ }^{29,30}$

\section{Methods}

Study approach: The research approach used for this study is qualitative and is based on social constructivist theory. A social constructivist approach aims to construct the meaning of social context and social reality. ${ }^{31-33}$ Guba and Lincoln believe that the human world is different from the natural world, which is studied by physical science, therefore, it must be studied differently as individuals construct and assign meaning to the world through their interpretation and interactions with it. ${ }^{34,35}$ Shadish reminds us that social constructionism means 'constructing knowledge about reality, not constructing reality itself.' 36 The intent of this approach is to use different sources of data in order to investigate the same phenomenon from different perspectives. ${ }^{35,37}$

Participants: This study employed mixed evaluation methods including: review of the current curriculum theories, models and ideologies, and four in-depth interviews and two focus group discussions conducted with nursing graduates and nursing lecturers. The participants were selected by non-probability purposive sampling to achieve theoretical sampling between the period of June and September 2008. ${ }^{38,39}$ The participants included fifteen nursing students and ten nursing tutors. The age of the participants ranged from 25-50 years. The size of sample was not fixed at the initial stage, as the size of sample and data collection occur simultaneously and the size of sample was decided based on the result of data analysis. ${ }^{40}$ Recruitment (data collection) continued until saturation of emerging major themes or categories was evident. ${ }^{41}$

Information gathering: A topic guide i.e. 'holistic injunction' was developed based on the literature reviews and the experience of the researchers (Box 1). ${ }^{42}$ The topic guide was identical for both students and tutors and sufficiently flexible to allow any relevant issues to be discussed. The topic guide used in this study was piloted with two nursing students and three nursing tutors (two men and three women) at the Nursing Department of Bharatpur Medical College (non-study area, but similar geo-political setting) to establish face validity as well as to improve the intrinsic aspects of the questions. ${ }^{38,43}$ Based on the feedback received, the guide was slightly revised and finalised for use in the three study sites- Kathmandu, Pokhara and Birgunj campuses of the Institute of Medicine.

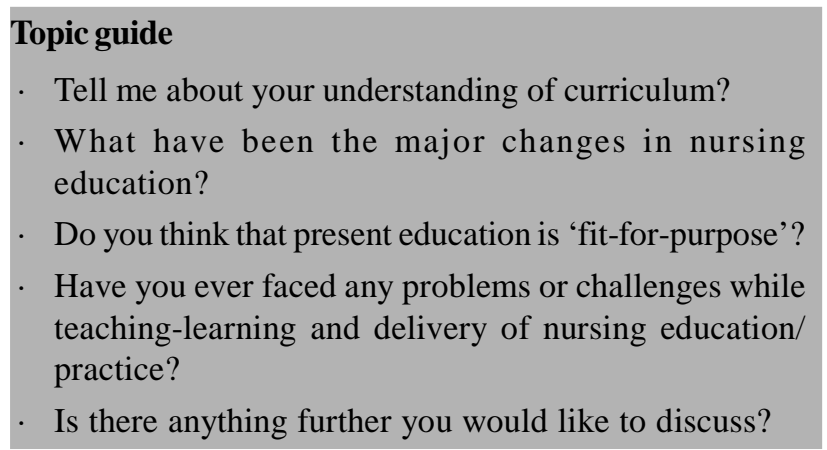

Data analysis: The interviews were audio-taped using a digital voice recorder after which they were transcribed verbatim including - 'pauses, emotional expressions, and annotations' into the computer using Microsoft@Word2003. ${ }^{44}$ The interviews were imported to QSRCNVivo7 software for qualitative data management and analysed to reveal coding structures: categories, subcategories, themes and codes. ${ }^{45}$ The NVivo7 enabled the exploration of each interview to identify words and phrases that formed the basis for the development of themes and sub-themes and it also enabled interviews to be interlinked. ${ }^{39,46}$ Transcribed versions were sent to selected participants, who were requested to check if they agreed with what was written. Any inconsistencies were corrected accordingly. Nepali versions of transcripts were translated into English. Two independent bilingual translators (Nepalese and English) verified the translations for accuracy. Relevant curriculum materials were reviewed and analysed in the light of (nursing) curriculum theories and models.

Ethical approval: Informed consent was obtained from individual participants before starting interview. Participants confidentiality and anonymity were maintained throughout by ensuring names were not reflected in the findings. In addition, participants were made free to participate, answer questions partially decline to answer, or even terminate the interview at any stage should they wish to do so.

\section{Results}

Background and characteristics of the respondents: Twenty-five respondents (two focus group discussions and 
four in-depth interviews with nursing students with 15 final year certificate level nursing students and 10 nursing tutorsacademic staff teaching/lecturing at a various institutions under the umbrella of Institute of Medicine) were recruited, using a convenience sample for the purpose of this study. The respondents were stratified by demographic attributes: age, sex, education, respondents' category and marital status. Most of the participants were between the ages of 25 and 45 years $(72 \%, n=18)$ (Table 1$)$.

Table 1: Frequency distributions of respondents by age, sex, education, respondent groups and marital status

\begin{tabular}{|c|c|}
\hline Distribution & Respondent (\%) \\
\hline \multicolumn{2}{|l|}{ Age group (in years) } \\
\hline 25 & $4(16)$ \\
\hline $25-35$ & $10(40)$ \\
\hline $35-45$ & $8(32)$ \\
\hline $45-50$ & $3(12)$ \\
\hline \multicolumn{2}{|l|}{ Sex } \\
\hline Male & $0(0)$ \\
\hline Female & $25(100)$ \\
\hline \multicolumn{2}{|l|}{ Entry qualifications } \\
\hline School Leaving Certificate (GCSC) & $6(24)$ \\
\hline Intermediate (A-level) & $3(12)$ \\
\hline Undergraduate (Bachelors degree) & $11(44)$ \\
\hline Postgraduate (Master/MPhil/PhD) & $5(20)$ \\
\hline \multicolumn{2}{|l|}{ Respondent category } \\
\hline Nursing Students & $15(60)$ \\
\hline Nursing Tutors & $10(40)$ \\
\hline \multicolumn{2}{|l|}{ Marital status } \\
\hline Married & $13(52)$ \\
\hline Single & $11(44)$ \\
\hline Widow & $1(4)$ \\
\hline Total & $25(100)$ \\
\hline
\end{tabular}

Findings from the interviews and discussions: Upon analysis of the transcripts, from the interviews and discussions, a number of themes emerged. A core category was arrived at, based on four broad themes and categories identified from the data. The themes are as follows:

\footnotetext{
nursing as career

gaps in curriculum

learning approach

problems and challenges
}

Themes were not mutually exclusive, but overlapped and contained contradictions, reflecting the complexity of the micro situation within its wider education context.

\section{Nursing as career}

Most of the nursing students expressed the importance of nursing education in practice; for example, practice based education and need (situation) based learning. The majority of the respondents $(60 \%, \mathrm{n}=15)$ gave two main reasons for choosing nursing: develop career (profession) and improve nursing practice (Fig. 1). Other key reasons are summarised below:

We choose nursing as a career because we want to be a force for good, and not just in the abstract. Nursing teaches the theory and skills that enables expert practitioners to meet individual patients' and clients' needs when they are at their most vulnerable. This willingness to do whatever it takes to provide essential care - even when it means nurses getting their hands dirty, literally this inspires public affection and informs the profession's own view of itself as caring. (NS 5, 6,7,12,11, NT 01, 04, 05, 07, 10)

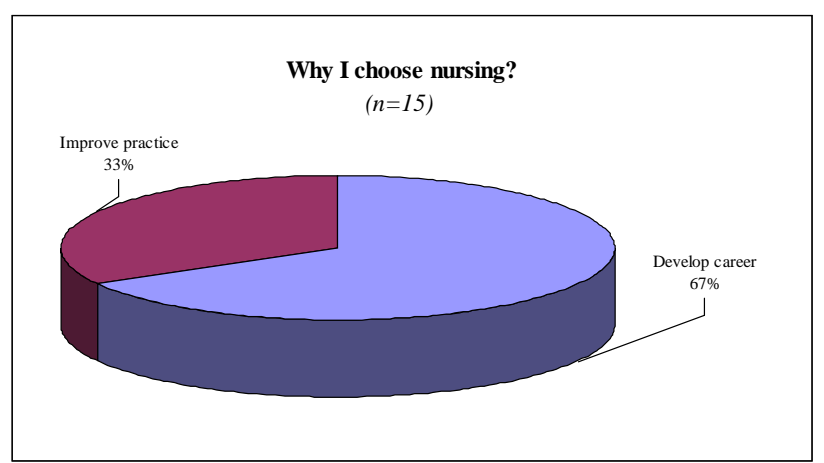

Fig. 1: Reasons for choosing nursing education

\section{Gaps in curriculum}

We found that there is no particular reference to a model applied to influence the design of present curricula. However, a conceptual framework 'wellness to illness model' does look at the ways curricula are designed and structured and, to this extent would be appropriate to review and analyse, using the curriculum theories and ideologies, the present curriculum.

The first model considered to review the curriculum was SPICES criteria (Student-centred, Problem-based, Integrated, Community-based, Electives, Systematic). ${ }^{47}$ This model considers six major criteria in the evaluation of a curriculum and it highlights student-centred vs. teachercentred learning; problem-based learning vs. information gathering; integrated vs. discipline-based teaching; community-based vs. hospital-based education; elective vs. standard; and systematic vs. opportunistic programme. ${ }^{47}$ Putting these criteria into this context, it appeared that the present curriculum deviates from the SPICES approach. In discussions with the nursing students, the majority $(66 \%$, $\mathrm{n}=10$ ) were reluctant to examine the curriculum in line with 
the SPICES model. ${ }^{47}$ However, one student strongly commented that:

The present curriculum is no longer corresponding with the positive version of the criteria. It is, in fact, otherwise around i.e. more on teacher-centred just for information gathering; discipline-based teaching; institution-based education; and focused within the nursing dimension rather than wider developmental perspective... it is rather narrow. (NS1)

It needs to identify content as 'need to know, good to know or nice to know' and to teach accordingly. (NS1)

The second model, the 'wellness-illness-model' has been considered as relevant because it is concerned with health maintenance/prevention vs. disease/acute care; individual vs. community based, and physical/biomedical model vs. behavioural science which is mostly consistent with the aims and objectives of the curriculum. ${ }^{48}$ The essential concepts in all nursing education models are the people, environment, and health. ${ }^{49}$

The Behavioural model, on the other hand, considered curriculum as a product. ${ }^{50}$ It further emphasised that to change students' behaviour, the curriculum should be articulated with students' thinking and feelings as well as overt action by stating the learning outcomes. Considering the limited information provided in the handbook and findings of discussions, we argue that it would be difficult to assess the degree of achievements as the learning objectives were too vague to measure, and the expected outcomes seemed inconsistent with set-standards (criteria); for example, it was not evidence-based. However, there are still opportunities for the application of the behavioural model in formulating learning outcomes by exemplifying real life scenarios. ${ }^{1,51}$

However, the process model stated that the role of planning and negotiation between teacher and student in the teaching-learning process, for example, in the selection of content, learning strategies and evaluation, is critical. ${ }^{17}$ This model further claimed that the 'value of students' and their role in the learning process has been considered as important. ${ }^{52,53}$ Using the position of nursing graduates in the given education context, we found that little emphasis was placed on giving students a 'valuable position' from the start of curriculum planning up to evaluation level. In fact, this curriculum demands teacher as an 'expert' in subject context. ${ }^{1}$ Thus, it could be justified that the overall learning strategies would be around 'curriculum-content' rather than education 'development context'. The best curriculum would aim to develop the learning objectives by negotiation with the students and would bring about their changes appropriately in the learning environment. ${ }^{15,17}$

\section{Learning approach}

Another important consideration in developing curriculum is found in the humanistic learning approach. This approach considers students as the centre of the learning spectrum and encourages them to develop their self-appraisal and motivation. ${ }^{53,54}$

One of the important aspects of reviewing the "process model' in light of the present curriculum is that the selection of appropriate teaching-learning content and methodologies, and evaluation strategies, are in place. ${ }^{14,55}$ However, another important aspect is the competency and quality of tutors. ${ }^{14}$ It has been noted that the majority of the respondents were from a pure medical/clinical nursing background. Therefore, we argue that, because of the control in the learning process i.e. more didactic-teaching, there is little room for revision and modification in the curriculum within the broader framework of the nursing process. ${ }^{55}$

Several respondents reported that:

Tutors' incompetence in teaching was one of the drawbacks as it affected the teaching-learning process. Still they are not up to date both for the 'subject contents' and 'context - e.g. IT, Blackboard learning, and students centred teaching. (NS 2, 6, 8, 9).

[This] curriculum content is mostly oriented towards the medical model with limited involvement in community imitative; inadequate emphasis on community orientation; inadequate teacher preparation; and isolation of nursing education from actual practice. (NS 6, 11).

Another respondent raised the concern that:

Lack of tutors' Continue Professional Development (CPD) in teaching was another constraint for underachievement. (NS 10).

We have noticed that the present curriculum has not been revised frequently, which we felt was a major challenge in terms of meeting the needs of students professional practice. ${ }^{3}$ In addition, we also observed that the existing curriculum developed without proper evidence; therefore it did not address the nursing needs and requirements at national and global levels. ${ }^{3}$ Thus, this paper supports that the application of the process model in assessing and evaluating the present curriculum found relevant in terms of selecting the appropriate strategies of teaching-learning process.

Similarly, cultural diversification, and its appropriate reflection into curriculum, was revealed as an important facet in Nepalese nursing education. ${ }^{3,4,6,7,9}$ As Lawton's cultural 
analysis suggest, this curriculum was developed by 'experts' from developed countries while Nepal had a shortage of nurses and the predominance of such cultural influences still exists in practice. ${ }^{56,1}$ Therefore, at this stage of evaluation, it can be argued that the purpose of nursing education has virtually failed to address the socio, geopolitical and cultural context in education. Humphrey further considered curriculum as a 'product' for marketing that would enable the creation or facilitation of a reciprocal relationship between service providers and purchasers. ${ }^{57}$ On reflection, it appears that Humphrey's model would be applicable to the revisions and modification of the curriculum in light of the changing educational reform in Nepal. ${ }^{57}$

Ensuring access to education to all levels of people, regardless of race, ethnic background and gender, is the national education policy in Nepal, but in practice this has not materialised and there is still a huge gap between different socioeconomic and political regions. ${ }^{8,58}$ One tutor comments that:

The democratic/liberal humanism model recognises the different levels of values, knowledge and cultures that would ultimately help to take a student-centred approach to nursing education in Nepal. (NT 9)

\section{Problems and challenges}

Nursing is a practice discipline. ${ }^{59}$ The education theory and practice gap has been debated for years, and from many different viewpoints.

In nursing education, theory takes precedence over the practice aspects of patient care and students often miss out an essential experience. (NS 01, 07)

If education were to become more practical, students need a balance between practice and theory. The practical sessions back up the theory they learn in class room. (NT 01,07)

This paper will not attempt to provide a solution to all problems; however we have tried to explore some options for the solution. It has been acknowledged that failures in nursing education may relate to failures in practice and theory. ${ }^{60}$ Therefore, JM Consulting Ltd, in their review of the Nursing and Midwifery Council (NMC) ${ }^{1}$ Act (46) refer to:

Still imperfect integration of theory and practice education and a feeling by many observers that practice education is given a lower priority than intended. ${ }^{61,62}$

Few nursing tutors suggested that students should learn from the workplace as much as in the classroom. ${ }^{14}$

Nurses (nursing students) do need a good understanding of practical skills but they (students) also need to know the theory that underpins their practice. (Brackets added; NT $01,07,09,10)$

Therefore, nurses and employers have a joint responsibility for continuous learning and the development of lifelong learning. ${ }^{14,17}$ There was a perception by some former nursing tutors that nurses were an underutilised resources whose talents were being constrained by dominating physicians and societal norms that limit acceptable roles of women. ${ }^{23,25,27}$. Thakur noted the similar concern of nursing education in Nepal:

If we do not upgrade our nursing campuses, nursing curricula and the standards of education, we will not only be discredited in the foreign market soon, but we will also fail to provide proper attention to the proper care of our patients. So, the nursing education needs comes first, before we reap the benefit of the profession internally and externally (internationally). ${ }^{3}$

One of the constraints that we found during the analysis was the gap between theory and practice and inadequate teaching-learning materials that are in national languages and culturally relevant (Fig. 2). One informant suggested that the lack of depth was leading to 'misunderstanding and misapplication of concepts.' (NT7). It is therefore considered that the education of nursing students should aim to minimise such a gap through combining theory and practice. ${ }^{63,64}$

In discussions about the gaps in the curriculum, respondents expressed specific points as major gaps in nursing education in Nepal (Table 2):

Firstly, though there is content of communication skills in the curriculum, teaching and learning methodology is not appropriate in light of intended objectives. Secondly, there is a general lack of appropriate teaching methodologies to impart essential skills and knowledge. Therefore, they suggest there should be separate mark to evaluate attitude in each and every subject for the moulding of behaviour. Thirdly, there is no relevant evaluation techniques- therefore it is difficult to maintain the characteristics of evaluation such as; validity, reliability, objectivity and usability. And finally, they suggest curriculum should be focused on skills competence or standardised as well as behavioural parts. (NS1,4,7,8,9,10 \& NT 1,7.19)

Two nursing students further disclosed their needs for cultural competence in nursing training:

I think that our tutors are not fully aware of the cultural needs of the students, it would be helpful to be more aware, and not find out when you put your foot in and have done 
something you should not.... (NS 1,4)

Another student was also equally concerned about delivering ethnic-specific education, feeling that training would not overcome intercultural differences, but rather that tutors should be from the same background as students:

We can't learn thousands of years of their way of life and their social levels and, all the things involved in that. As well as, they have got to deliver the education because it's difficult to read problems that are not of the same ethnic group and their socio-psychological reactions. (NS 13)

Table 2: Key results from the study

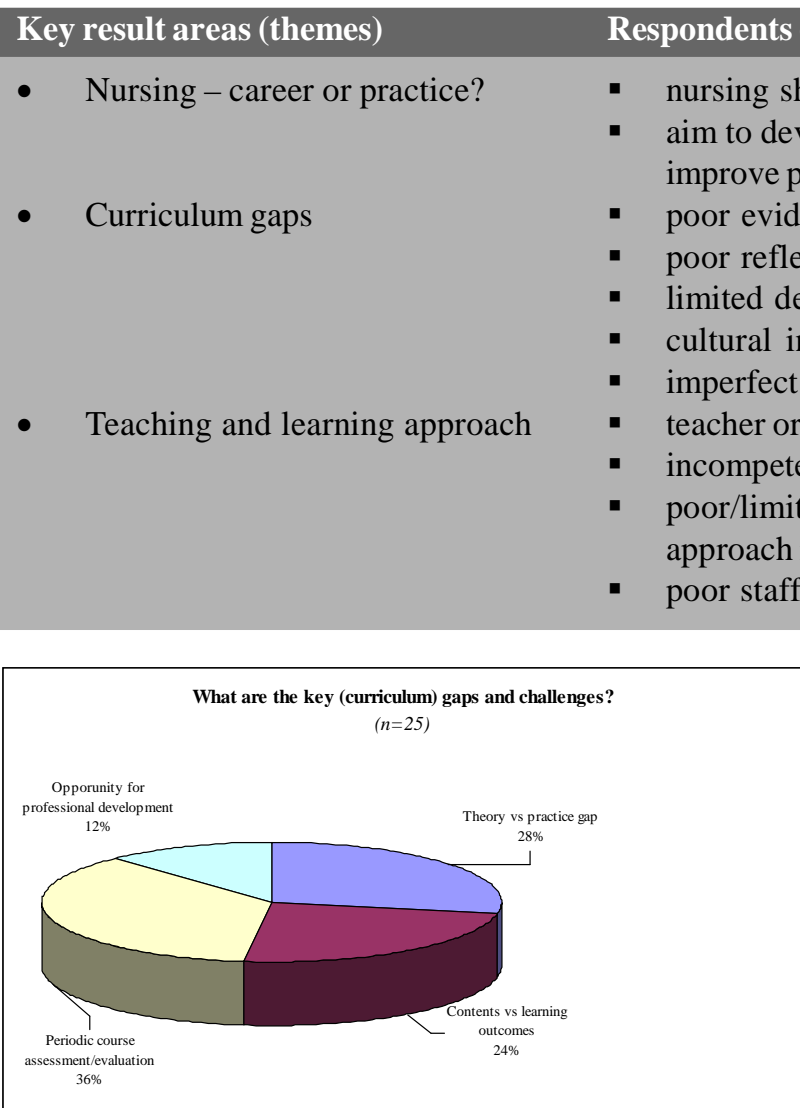

Fig. 2: Curriculum gaps and challenges

\section{Discussion}

Based on our knowledge, this was the first study of its kind in Nepal - evaluating a 3-year undergraduate certificate nursing curriculum using the perspectives and perceptions of both nursing students' and nursing tutors' as well as review of the relevant curriculum theories and models. The results of the current study confirm and enhance those from previous studies. ${ }^{12,19,21,23,25-28,56}$ giving further evidence of nursing education and its possible effect on care and services. Strength of this study is that both groups of participant -students and tutors- got the opportunity to express their experiences and feelings as these groups can be considered as core groups in the health care system. The nursing profession is often concerned with the assessment and evaluation of nursing education as there is no system for monitoring the implementation of nursing education against identified standards. ${ }^{9,65}$ However, little attention has been paid to the topic of nursing education in the context of Nepal. ${ }^{1}$ As Salsali suggests that the assessment and evaluation of curriculum should be fair and impartial. $^{9}$

mments on current nursing curriculum 
course, definitely needs to be increased. Practice is also a method of keeping skills updated. ${ }^{66}$

One way of approaching this is to focus on how students learn and gain professional knowledge and to combine it in education. ${ }^{67}$ Candy proposed that the development of lifelong learners and professionals requires the provision or adoption of curriculum with a structure for the incremental development of self-directed learning. ${ }^{68}$ Davis and Wong et al. further consider that reflective learning is the best way to learn by integrating theory with practice so that students will learn from their 'own-world' and turn their experiences into new learning. ${ }^{69,70}$ To make the readers more aware about the subject matter i.e. 'curriculum and evaluation', limited comparative analyses with previous studies were performed and quoted some useful observations.

Limitation of study: The study had some limitations. This study is limited to a small sample size, using a purposiveconvenience sampling method, hence generalisation of the findings is not possible. The study is also limited to a specific group of population; thus, findings are relevant only to the specified group in the study.

\section{Conclusions}

This study suggests that the level of nursing education could be improved by (faculty) management's attention to curriculum development and implementation, as well as regular evaluation and analysis of curriculum. It reinforces evidence from previous studies regarding the likely impact of curriculum at individual and professional education and practice. Study noted that nursing curriculum demands both theory and practice which also considers students at the centre of the learning process. Therefore, this paper concludes that the selection of appropriate teachinglearning methodologies is essential to develop competent nurses who can deliver comprehensive care and contribute effectively to health services in Nepal.

\section{Acknowledgement}

Authors would like to thank Nic Hughes, University of Leeds, UK, for his support in preparing this manuscript.

\section{References}

1. Institute of Medicine. Certificate nursing curriculum handbook. 4th ed. Kathmandu, Nepal: Tribhuvan University Health Learning Materials Centre; 1997.

2. Gubhaju B. Child mortality and survival in South AsiaNepalese perspective. New Delhi, India: 1991. p. 214.
3 Thakur LS. Fifty years of nursing education. [Online]. 2006 Dec 2 [cited 2009 Mar 8]; Available from: URL: http:/ /www.kantipuronline.com/kolnews.php?\&nid=93347

4 Streefland P. The frontier of modern western medicine in Nepal. Soc Sci Med. 1995; 20:1151-9.

5. Karki DB, Dixit H. An overview of undergraduate and postgraduate medical education in Nepal and elsewhere. Kathmandu Unvi Med J (KUMJ). 2004 JanMar;2(1):69-74.

6. Health Learning Materials Project. Certificate nursing curriculum. 2nd ed. Kathmandu, Nepal: Institute of Medicine, Tribhuvan University; 1987.

7. Health Learning Materials Project. Post basic bachelor of nursing curriculum. Kathmandu, Nepal: Institute of Medicine, Tribhuvan University; 1989. p. 57.

8. Ministry of Health. Annual progress report. Nepal. MoH: 2001.

9. Salsali M. Evaluating teaching effectiveness in nursing education: an Iranian

perspective. BMC Med Educ. 2005 Jul 27;5:29.

10. Ogilvie L. Issues in nursing education in Nepal. Nurse Educ Today. 1998 Jan;18(1):72-8.

11. Barrett M, Margaret A, Carol S. Evaluating the graduates of the Dalhousie University School of Nursing baccalaureate programme: a quantitative/ qualitative responsive model. J Adv Nurs. 1996;24:1070-6.

12. World Health Organization. Developing health human resources: developing countries. Geneva, Switzerland: WHO; 1992.

13. Nepal Nursing Council. Regulation for postgraduate nursing education. Nepal Nursing Council; 2002.

14. Quinn F. Principle and practice of nurse education. 4th ed. London: Cheltenham; 2000.

15. Jarvis P. Reflective practice and nursing. Nurse Educ Today. 1992;12:174-81.

16. Pratt D. Curriculum design and development. Chicago: Harcourt Brace

Jovanovich International Edition; 1980. p. 530.

17. Stenhouse L. An introduction to curriculum research and development. London: Heinemann; 1988.

18. Carroll M, Curtis L, Higgins A, Nicholl H, Redmond R, Timmins F. Is there a place for reflective practice in the nursing education? Nurse Educ Pract. 2002;2:13-20. 
19. Gallego A. Curriculum planning in nursing education. Nurse Educ Today. 1991;12:76.

20. VanOrt S. Developing a system for documenting teaching effectiveness. J Nurs Educ. 1983;22:324-8.

21. Toffler A. Future shock. [Online]. 1971 [cited 2006 Jan 12]; Available from: URL: http://www.ou.edu/englhale/ toffler.html

22. Bapat SK, Jha N. Nepal: Medical Education - Changing perspectives. Kathmandu Uni Med J. 2005;3:159-64.

23. Cork N. Approaches to curriculum planning. In: Davis B, editor. Nursing Education: Research and Developments. New York: McGraw-Hill; 1997. p. 3498.

24. Ben-Zur H, Yagil D, Spitzer A. Evaluation of an innovative curriculum: nursing education in the next century. J Adv Nurs. 1999 Dec;30(6):1432-40.

25. Jolley M. The weight of tradition - An historical examination of early educational and curriculum development. In: Allan P, Jolley M, editors. Curriculum in nursing education. London: Helm; 1987. p. 68-132.

26. Hegge $M$. Restructuring registered nurse curricula. Nurs Educ. 1995 Nov-Dec;20(6):39- 44. Review.

27. Norman G. Research in medical education: three decades of progress. BMJ. 2002 Jun 29;324(7353):15602.

28. Booth RZ. Leadership challenges for nurse practitioner faculty. Nurse Pract. 1995 Apr;20(4):52-60.

29. Chiu T, Lee S. Development of basic nursing education in China. Proceedings of the First China-Hong Kong Nursing Education Conference. The Hong Kong Polytechnic University, Hong Kong, 1996.

30. Chan S, Frances W. Development of basic nursing education in China and Hong Kong- issues and innovations in nursing education. J Adv Nurs. 1999;29:1300-7.

31. Somekh B, Burman E, Delamont S, Meyer J, Payne M, Thorpe R. Research communities in social science. In: Somekh B, Lewin C, editors. Research methods in the social sciences. London: Sage Publications; 2005. p. 144.

32. Babbie E. The practice of social research. 11th ed. Belmont: Wards Worth/Thompson Learning Inc; 2007.

33. Denzin N, Lincoln Y. Handbook of qualitative research. 2nd ed. Thousand Oaks: Sage Publications; 2000.
34. Guba E, Lincoln Y. Can there be a human science? Person-Centred Review. 1990;5:130-54.

35. Patton Q. Qualitative research and evaluation methods 3rd ed. London: Sage Publications; 2002.

36. Shadish W. Philosophy of science and the quantitativequalitative debates: thirteen common errors. Eval Program Plan. 1995;18:63-75.

37. Neimeyer G. Constructivist assessment: a casebook. Newbury Park, CA: Sage Publications; 1993. p. 248.

38. Bowling A, Ebrahim S. Handbook of research methods: investigation, measurement and analysis. London: Open University Press; 2005.

39. Ritchie J, Lewis J. Qualitative research practice: A guide for social science students and researchers. London: Sage publications; 2003.

40. Glaser B, Strauss A. The discovery of grounded theory: Strategies for qualitative research. 2nd ed. Chicago: Aldine; 1967.

41. Mason J. Qualitative researching. 2nd ed. London: Sage Publications; 2002.

42. Noblit G, Engel J. The holistic injunction: an ideal and a moral imperative for qualitative research. Qual Health Research. 1991;1:123-30.

43. Robson C. Real world research: a research for social scientists and practitioners-researchers. Oxford: Blackwell publication; 2002.

44. Crabtree B, Miller W. Doing qualitative research. London: Sage Publications; 1999.

45. Strauss A, Corbin J. Basics of qualitative research: techniques and procedures for developing grounded theory. 2nd ed. Newbury Park, CA: Sage Publications; 1998.

46. Lewis A, Silver C. Using software qualitative research: a step-by-step guide. London: Sage Publications; 2007.

47. Harden RM, Sowden S, Dunn WR. Educational strategies in curriculum development: the SPICES model. Med Educ. 1984 Jul;18(4):284-97.

48. Cusimano M, Garg M. A scale for curriculum evaluation and development in the health professions. Eval Health Prof. 1996 Mar;19(1):91-103.

49. Shamsudin N. Can the Neumann Systems Model be adapted to the Malaysian nursing context? Nurse Educ Today. 2002;2:210-23. 
50. Tyler R. Basic principles of curriculum and instruction. Chicago: University of Chicago Press; 1969. p. 134.

51. Heidari F, Galvin K.. Action learning groups: can they help students develop their knowledge and skills? Nurse Educ Pract. 2003 Mar;3(1):49-55.

52. Knowles M. The adult learner: A neglected species. 4th ed. Houston: Gulf Publishing; 1990.

53. Kolb D. Experiential leaning: experience as the source of learning and development. NJ: Prentice Hall; 1984.

54. Rogers C, Freiberg HJ. Freedom to Learn. 3rd ed. New York: MacMillan; 1994.

55. Roper N, Logan W, Tierney A. The elements of nursing: A model for nursing based on a model of living. 4th ed. Edinburgh: Churchill Livingstone; 1996.

56. Lawton D. Curriculum studies and education planning. London: Hodder and Stoughton; 1983.

57. Humphrey J. New model in a corporate paradigm. In: Humphrey J, Quinn FM, editors. Healthcare education: the challenge of the market. London: Chapman and Hall; 1994. p. 68-132.

58. UNDP. Nepal Human Development Report. [Online]. 2005 [cited 2007 Apr 10]; Available from: URL:http://www.undp.org.np/publications/nhdr2005/ index.html

59. Pang SM, Wong TK, Dorcas A, Lai CK, Lee RL, Lee WM, et al. Evaluating the use of

developmental action inquiry in constructing a problembased learning curriculum for pre-registration nursing education in Hong Kong: a student perspective. J Adv Nurs. 2002 Oct;40(2):230-41.

60. Ferguson KE, Jinks AM. Integrating what is taught with what is practised in the nursing curriculum: a multi-dimensional model. J Adv Nurs. 1994 Oct;20(4):687-95.

61. JM Consulting Ltd. Review of the Nurses, Midwives and Health Visitors Act. Bristol: JM Consulting Ltd; 1997.

62. Nursing and Midwife Council (NMC). Code of professional conduct. London: NMC; 2000.

63. Frost M. An analysis of the scope and value of problem-based learning in the education of health care professionals. J Adv Nurs. 1996 Nov;24(5):1047-53.

64. Heliker D. Meeting the challenge of the curriculum revolution: problem-based learning in nursing education. J Nurs Educ. 1994 Jan;33(1):45-7.

65. Wong FK, Kember D, Chung LY, Yan L. Assessing the level of student reflection from reflective journals. J Adv Nurs. 1995 Jul;22(1):48-57.

66. Batalden P, Stoltz P. A framework for the continual improvement of health care: building and applying professional and improvement knowledge to test change in daily work. Jt Comm J Qual Improv. 1993;19:432-52.

67. Candy P. Reaffirming a proud tradition: universities and lifelong learning. London: Active Learning in Higher Education; 2000. p. 101-26.

68. Davis E. Teachers as curriculum evaluators. London: George Allen and Unwin; 1980.

69. Boud D, Keogh R, Walker D. Reflection: Turning learning into experience. London: Kogan Page; 1985.

70. Turner P, Hunt LA. Integrating practice into theory in the new nursing curriculum Nurse Educ Pract. 2003 Dec;3(4):228-35. 